\title{
CORRECTIONS
}

\section{Prison environment and health}

In this Analysis article and subsequent articles in the series on prison health, Sue Gauge was wrongly named as Claire in the acknowledgments section and Alex Gatherer, temporary adviser to WHO world health in prisons programme, was omitted (BMJ 2012;345:e5921, doi:10.1136/bmj.e5921; BMJ 2012;345:e6263, doi:10.1136/bmj.e6263; BMJ 2012;345:e7280, doi:10.1136/ bmj.e7280; BMJ 2013;346:e8318, doi:10.1136/bmj.e8318; BMJ 2013;346:f2216, doi:10.1136/bmj.f2216).

Cite this as: BMJ 2013;346:f2554

๑ BMJ Publishing Group Ltd 2013 